\title{
Synovium as a Source of Interleukin 6 In Vitro \\ Contribution to Local and Systemic Manifestations of Arthritis
}

Pierre-André Guerne, Bruce L. Zuraw, John H. Vaughan, Dennis A. Carson, and Martin Lotz

Department of Basic and Clinical Research, Research Institute of Scripps Clinic, La Jolla, California 92037

\section{Abstract}

Synovial inflammation is often associated with systemic changes, such as increased levels of acute phase proteins and hypergammaglobulinemia, which cannot be explained by the cytokines described in synovial fluids and synoviocyte secretions. Interleukin 6 (IL-6) has recently been characterized as a mediator of multiple inflammatory responses. This cytokine promotes $\mathrm{T}$ and $\mathrm{B}$ lymphocyte growth and differentiation, and acute phase protein synthesis. We therefore examined IL-6 production by human synoviocytes and its presence in synovial fluids. In vitro, synoviocytes spontaneously released IL-6, which was increased by IL-1 and tumor necrosis factor- $\alpha$. Synoviocyte-derived IL-6 activity was able to induce hybridoma-plasmacytoma proliferation, and immunoglobulin and acute-phase protein synthesis. The synovial fluids from patients with diverse arthropathies contained IL-6 activity, but higher levels were present in inflammatory arthropathies than in osteoarthritis. These results demonstrate that synoviocytes are a potent source of IL-6, which can contribute to important manifestations of inflammatory arthropathies.

\section{Introduction}

Rheumatoid arthritis is a chronic autoimmune disorder that is mainly expressed in joints, but which also has multiple systemic manifestations. Hypergammaglobulinemia (1) and elevated levels of acute-phase proteins are regular systemic features of this disease. The synovial membrane is hyperplastic and infiltrated with mononuclear cells (2-5). T lymphocytes in the inflamed synovium are activated (6) and B lymphocytes produce rheumatoid factor (7). Synoviocytes probably play a central role in this process. They are located at the site of tissue destruction and secrete proteases that degrade cartilage, as well as other mediators of inflammation and tissue damage (reviewed by Dayer and Demczuck [8]). The cytokines that have been shown to be released by synoviocytes can explain some but not all the systemic manifestations of the disease. Interleukin 1 (IL-1) and tumor necrosis factor- $\alpha$ (TNF- $\alpha)^{1}$ are thought

This is Publication No. 5380BCR from the Research Institute of Scripps Clinic.

Received for publication 27 May 1988 and in revised form $17 \mathrm{Au}$ gust 1988.

1. Abbreviations used in this paper: BSF-2, B cell-stimulating factor 2; $\mathrm{CIINH}, \mathrm{Cl}$ esterase inhibitor; HGF, hybridoma growth factor; HSF, hepatocyte-stimulating factor; LT, lymphotoxin; (r), recombinant; SN, supernatant; TNF- $\alpha$, tumor necrosis factor- $\alpha$.

J. Clin. Invest.

(c) The American Society for Clinical Investigation, Inc.

$0021-9738 / 89 / 02 / 0585 / 08 \quad \$ 2.00$

Volume 83, February 1989, 585-592 to play a central role in mediating inflammatory joint destruction through their ability to stimulate production of proteases and prostaglandins by synoviocytes and bone resorption by osteoclasts (9-11). Recently, IL-1 and TNF- $\alpha$ have been shown to be potent inducers of IL-6 synthesis (12-14). IL-6 is now known to be a central mediator of host defense responses, affecting growth and differentiation of a wide spectrum of cells. It induces the final maturation of B lymphocytes into Ig-producing cells $(15,16)$, stimulates growth of plasmacytoma and hybridoma cells (17), and is identical to the IL-1-induced $26-\mathrm{kD}$ protein in fibroblasts (18). IL-6 has also been shown to have hepatocyte-stimulating factor activity, thereby regulating the major acute-phase protein response (19), to be a costimulant for human thymocytes and T lymphocytes (20), to be involved in the differentiation of cytotoxic $T$ lymphocytes (21), and to enhance IL-3-dependent proliferation of multipotential hemopoietic progenitors (22). Additionally, there is suggestive evidence to indicate that IL-6 may regulate fibroblast proliferation (23). The results reported here show that IL-6 is spontaneously produced by synoviocytes and that IL-1, TNF- $\alpha$, and lymphotoxin (LT) augment its synthesis. Very high levels of IL-6 are present in synovial fluids obtained from patients with inflammatory arthropathies. Synoviocyte-derived IL- 6 can stimulate immunoglobulin synthesis, hybridoma and plasmacytoma growth, and acute-phase protein production.

\section{Methods}

Synoviocyte isolation and culture. Synoviocytes were isolated from surgical specimens freshly removed from patients undergoing knee or hip joint replacement. Collagenase digestion and culture were performed as described (24). Synoviocytes were maintained in DME supplemented with L-glutamine, penicillin, streptomycin, and $10 \%$ fetal calf serum (FCS). At confluency the cells were trypsinized and recultured.

Monocyte isolation and culture. Peripheral blood mononuclear cells were obtained by histopaque gradient sedimentation and monocytes were isolated by adherence to petri dishes as described (25).

Synoviocyte stimulation. At different passages, synoviocytes were transferred to 24 -well plates $\left(10^{5}\right.$ per well) in DME supplemented with $10 \%$ FCS. At confluency, usually after $1 \mathrm{~d}$, cells were washed and $1 \mathrm{ml}$ of fresh medium was added (DME supplemented with $1 \%$ FCS if not otherwise indicated) with the different stimuli. The supernatants $(\mathrm{SN})$ were collected at the time points indicated, centrifuged, and stored at $-20^{\circ} \mathrm{C}$ until they were tested for the presence of IL-6. Skin fibroblasts and peripheral blood monocytes were stimulated in a similar fashion.

IL-6 bioassays. (a) Hybridoma growth factor (HGF) assay: the B9.9 murine hybridoma (26) was maintained in RPMI 1640 supplemented with penicillin, streptomycin, L-glutamine, $10 \%$ FCS, and $0.2 \% \mathrm{vol} / \mathrm{vol}$ supernatant from poly $(\mathrm{rl})$ :poly $(\mathrm{rC})$-stimulated human skin fibroblasts as a source of IL-6. To perform the IL- 6 assays, cells were washed five times and 10,000 cells were added per well in flatbottomed, 96-well plates supplemented with serial dilutions of the samples to be tested in a final volume of $150 \mu \mathrm{l}$ of RPMI 1640 containing L-glutamine, penicillin, streptomycin, and 5\% FCS, in tripli- 
cates. After $48 \mathrm{~h}, 1 \mu \mathrm{Ci}$ of $\left[^{3} \mathrm{H}\right]$ thymidine was added to each well and the cells were incubated for $4 \mathrm{~h}$ more before harvesting onto glass fiber filters. Radioactivity was quantified by liquid scintillation counting. In each assay a standard curve using recombinant $B$ cell-stimulating factor 2 ([r]BSF-2) (27) was included. One unit of IL-6 in culture SN'was defined as the reciprocal of the dilution giving half-maximal stimulation. In this assay (r)BSF-2 is typically detected at $0.08 \mathrm{pg} / \mathrm{ml}$ and its specific activity is $125 \mathrm{U} / \mathrm{ng}$. (b) BSF-2 assay: (r)BSF-2 activity was quantified as induction of IgG secretion by the human B lymphoblastoid cell line CESS (28). The CESS cells were maintained in RPMI 1640 supplemented with penicillin, streptomycin, L-glutamine, and $10 \%$ FCS. For the assay, cells were washed and cultured $(5,000$ per well in 96-well, flat-bottomed plates) in the presence of various concentrations of test samples in a total volume of $150 \mu \mathrm{l}$ per well in RPMI 1640 containing $5 \%$ of FCS in triplicates. After $5 \mathrm{~d}$, the SN were collected. The concentration of IgG was then determined by ELISA (29). The activity of the SN was compared to (r)BSF-2. In this assay it was detectable at $0.2 \mathrm{pg} / \mathrm{ml}$ and its specific activity was $40 \mathrm{U} / \mathrm{ng}$. (c) Assay for hepatocyte-stimulating factor (HSF) activity: we have previously demonstrated that IL-6 is a potent inducer of $\mathrm{Cl}$ esterase inhibitor (C1INH) in the human hepatoma cell line HepG2 (Zuraw, B., and M. Lotz, manuscript submitted). These cells were maintained in RPMI 1640 supplemented with penicillin, streptomycin, L-glutamine, and $10 \%$ FCS. For the assays, they were trypsinized and plated in microtiter wells (flat-bottomed, 96-well plates) at 10,000 per well. At confluency, the medium was removed and replaced with $150-\mu 1$ aliquots of fresh RPMI 1640 supplemented with 5\% FCS and various concentrations of the $\mathrm{SN}$ to be tested. After $4 \mathrm{~d}$ the plates were centrifuged and the HepG2 SN were removed and stored at $-20^{\circ} \mathrm{C}$ until their content of $\mathrm{C} 1 \mathrm{INH}$ was assayed by ELISA (25). None of the agents used to induce IL-6 production in synoviocytes (IL-1, TNF, LT, Poly(I):(C)) had IL-6-like activity on CESS, B9.9, or HepG2 cells nor any synergistic activity with IL-6.

Antibody neutralization studies. Aliquots of culture SN were preincubated for $2 \mathrm{~h}$ at $37^{\circ} \mathrm{C}$ with rabbit antiserum to BSF-2 (30) or with preimmune rabbit $\mathrm{IgG}(1-10 \mu \mathrm{g} / \mathrm{ml})$ before addition to the cells used in the IL-6 assays.

Metabolic labeling and immunoprecipitation. Confluent synoviocyte cultures in 24-well plates were washed three times with Hank's balanced salt solution, and cultured for $24 \mathrm{~h}$ in $500 \mu \mathrm{l}$ of methioninefree RPMI 1640 medium containing $\left.1 \% \mathrm{FCS}, 20 \mu \mathrm{Ci} / \mathrm{ml}^{35} \mathrm{~S}\right]-$ methionine (No. 51006, ICN, Irvine, CA) and the various stimuli to be tested. After $24 \mathrm{~h}$, the SN were collected, centrifuged, and stored at $-20^{\circ} \mathrm{C}$ until analyzed. The SN were concentrated to $50 \mu$ l with ultraspin concentrators (Ultracent, Bio-Rad Laboratories, Richmond, CA). They were then precleared by a 1-h incubation with an equal volume of $10 \%$ protein A agarose (\#10-1041-5, Zymed, San Francisco, CA) in Net2 buffer ( $50 \mathrm{mM}$ Tris pH 7.4, $0.5 \% \mathrm{NP} 40,150 \mathrm{mM} \mathrm{NaCl}, 5 \mathrm{mM}$ EDTA, $0.02 \%$ sodium azide, $0.5 \%$ sodium deoxycholate, 0.1 sodium dodecylsulfate $)+$ protease inhibitors $(2 \mathrm{mg} / \mathrm{ml}$ soybean trypsin inhibitor, $5 \mathrm{mM}$ leupeptin, $5 \mathrm{mM}$ antipain, $0.1 \mathrm{mM}$ phenylmethylsulfonyl fluoride) with gentle shaking at $4^{\circ} \mathrm{C}$. The SN were recovered after centrifugation and incubated with $10 \mu \mathrm{l}$ of anti-IL-6 $(1 \mathrm{mg} / \mathrm{ml})$ overnight at $4{ }^{\circ} \mathrm{C}$ with gentle shaking. Then an equal volume of $10 \%$ protein A agarose in Net 2 buffer was added and incubation was continued for an additional $3 \mathrm{~h}$. The precipitates were washed seven times in Net 2 at $4^{\circ} \mathrm{C}$, resuspended in $50 \mu \mathrm{l}$ of sample buffer $(0.0625 \mathrm{M}$ Tris, $\mathrm{pH} 6.8,3 \%$ SDS and $10 \%$ glycerol containing $0.025 \%$ bromphenol blue) and boiled for $5 \mathrm{~min}$. The agarose beads were pelleted by centrifugation and the supernatants were separated on $15 \%$ SDS-polyacrylamide gels according to the method of Laemmli (31). Before autoradiography, the gels were dehydrated by washing twice in dimethylsulfoxide, dried, and impregnated for $1 \mathrm{~h}$ with 2,5-diphenyloxazole-dimethylsulfoxide (NEF-964, Dupont Co., Boston, MA).

Synovial fluids. The synovial fluids, obtained from patients undergoing routine arthrocentesis, were collected into heparinized tubes, diluted five times in RPMI 1640 , centrifuged at $2,000 \mathrm{~g}$ for $10 \mathrm{~min}$ to remove cells, and stored at $-20^{\circ} \mathrm{C}$ until they were analyzed.
Reagents. TNF- $\alpha$, sp act $5.02 \times 10^{7} \mathrm{U} / \mathrm{mg}$ and TNF- $\beta$ (LT), sp act $1.2 \times 10^{8} \mathrm{U} / \mathrm{mg}$, were kindly provided by $\mathrm{Dr}$. H. M. Shepard, Genentech Inc., South San Francisco, CA; IL-1 $\beta$, was donated by Dr. C. A. Dinarello, Tufts University Medical School, Boston, MA; (r) BSF-2 (16) and the polyclonal rabbit anti-BSF-2 ( $\mathrm{IgG}$ fraction, $1 \mathrm{mg} / \mathrm{ml}$ ) were generously provided Drs. T. Hirano and T. Kishimoto, Institute for Molecular and Cellular Biology, Osaka University, Osaka, Japan. The endotoxin content of the concentrated stocks of the lymphokine preparations was less than $0.006 \mathrm{ng} / \mathrm{ml}$ (Limulus amebocyte lysate assay). Purified endotoxin (lipopolysaccharide), from E. coli was purchased from Sigma Chemical Co., St. Louis, MO.

\section{Results}

IL-6 production by synoviocytes. When synoviocyte culture supernatants were tested on a subclone of the B9.9 hybridoma cell line, which is very sensitive to IL- 6 but does not respond to a large panel of human cytokines, IL- 6 activity was consistently detected in the absence of added stimuli (Fig. 1). Both primary explants of synoviocytes $(\mathrm{P} 1)$ that were examined $5 \mathrm{~d}$ after their removal from the joint, as well as synovial cells cultured up to five passages (more than $7 \mathrm{wk}$ ), released similar amounts of IL-6. No significant difference in the amounts of IL-6 released was noted between rheumatoid arthritis and osteoarthritis synoviocyte cultures. Synoviocytes derived from an avascular necrosis specimen as well as normal skin fibroblasts that were cultured under the same conditions also released similar amounts of IL-6 (data not shown). The addition of IL-1 to both early and late synoviocyte cultures augmented IL-6 production (Fig. 1). To rule out the possibility that contaminating lipopolysaccharide was responsible for this activation, similar experiments were repeated in the presence of polymixin B $(12.5 \mu \mathrm{g} / \mathrm{ml})$. IL-6 activity released by control and IL-1-stimulated synoviocytes was not significantly changed by

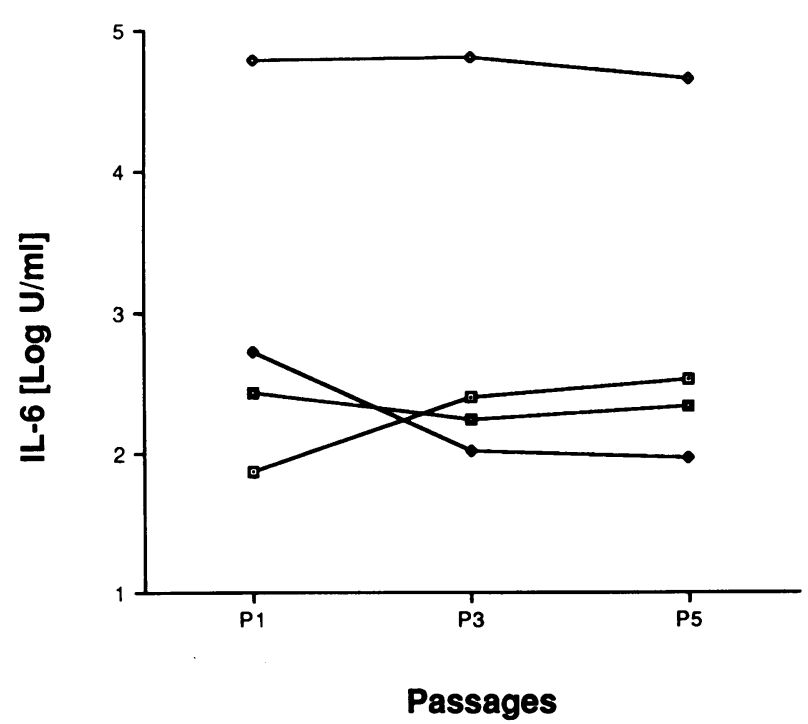

Figure 1. Spontaneous IL-6 release by synoviocytes. Different synoviocyte cell lines from rheumatoid arthritis $(R G[\square]$ and $R D[\bullet])$ and osteoarthritis $(O A[\square])$ were studied at passages 1,3 , and 5 , and cultured in DME supplemented with $1 \%$ FCS alone $(C)$ and in one case with IL-1 $(2 \mathrm{ng} / \mathrm{ml})$ for comparison $(R G I L-1[\diamond])$. The $\mathrm{SN}$ were collected after $72 \mathrm{~h}$ and tested for IL-6 activity in the B9.9 hybridoma cell proliferation assay. The results are mean values of triplicates (SE $<10$ ) of three representative cultures. 
the addition of polymixin B which completely inhibited the IL-6-inducing effect of lipopolysaccharide at doses up to 10 $\mathrm{ng} / \mathrm{ml}$ (data not shown). To evaluate whether serum constituents were responsible for the IL- 6 production by nonstimulated synoviocytes, cultures were performed with various concentrations of FCS. The results indicated that FCS was necessary since no IL-6 activity was detectable in cultures without serum. However, a maximal serum effect was already seen at $1 \%$ FCS with no further increase at $5-10 \%$. An analysis of the time course of the IL- 6 release showed that the cytokine was already detectable at $2 \mathrm{~h}$ in control cultures and at higher titers in cultures induced with IL-1 (Fig. 2). Levels further increased reaching submaximal levels by $24 \mathrm{~h}$, with only slight additional increases thereafter.

Cytokine regulation of synoviocyte IL-6 production. To evaluate factors that might be important physiological regulators of IL- 6 production, we tested the effects of IL-1, TNF- $\alpha$, and LT (TNF- $\beta$ ) on synoviocyte cultures. Fig. 3 summarizes the results of three representative experiments showing that all three cytokines enhance IL- 6 release. Of note is the difference in the potency of these three cytokines. When tested between 0.2 and $20 \mathrm{ng} / \mathrm{ml}$, IL- 1 was most active; at $20 \mathrm{ng} / \mathrm{ml}$ it increased IL- 6 by more than 350 -fold compared to unstimulated cultures. TNF- $\alpha$ was slightly less potent, with a 120 -fold increase at the same concentration. The increase induced by LT was much smaller and was detectable only at the highest concentrations: $20 \mathrm{ng} / \mathrm{ml}$ increased IL- 6 release by only 2.5 -fold. These experiments also show that the responsiveness of synoviocytes derived from osteoarthritis and rheumatoid arthritis patients is not significantly different. Synoviocytes from avascular necrosis specimens and skin fibroblasts have also been tested under these conditions and the pattern of IL- 6 release was similar (data not shown). Finally, as illustrated in Fig. 3, the number of passages did not significantly alter cytokine-induced IL-6 production.

Functional characterization of synoviocyte IL-6 activity. Having established that synoviocytes produce IL-6 activity as measured in HGF and plasmacytoma growth factor assays

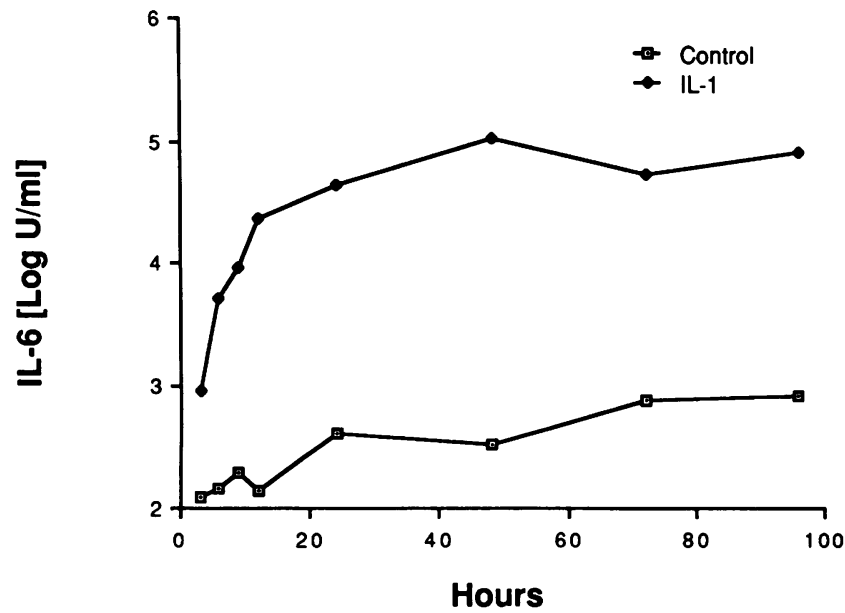

Figure 2. Kinetics of IL-6 production by synoviocytes. Rheumatoid arthritis synoviocytes were cultured either in medium alone or in the presence of IL-1 $(2 \mathrm{ng} / \mathrm{ml})$. SN were collected at the time points indicated and assayed for IL- 6 activity as proliferation of hybridoma cells. Results are mean values of triplicates (SE $<15 \%)$. (data not shown), we sought to determine whether the synoviocyte-derived material would have the other important IL-6 effects relevant to rheumatoid arthritis and other inflammatory arthropathies. Thus SN were tested for the ability to enhance production of Ig (BSF-2 activity) and of acute-phase protein (HSF activity). Fig. 4 shows that in the BSF-2 assay, which is less sensitive than the hybridoma growth factor assay, unstimulated synoviocyte culture SN slightly but consistently enhanced IgG production by the human lymphoblastoid cell line CESS, corresponding to a mean of $1.6 \mathrm{U} / \mathrm{ml}$ when compared with human (r)BSF-2. Supernatants from synoviocytes stimulated with IL-1, TNF- $\alpha$, and LT $(20 \mathrm{ng} / \mathrm{ml})$ had increased levels of IL-6. The highest levels $(>6,500 \mathrm{U} / \mathrm{ml})$ were induced by IL-1. We then analyzed the effect of synoviocyte $\mathrm{SN}$ on production of $\mathrm{CIINH}$, an acute-phase protein that is induced specifically by IL- 6 in the human hepatoma cell line HepG2 (Zuraw, B., and M. Lotz, manuscript submitted). Fig. 5 shows that synoviocyte supernatants contained significant HSF activity, which was higher when the synoviocytes were stimulated with IL-1, TNF- $\alpha$, or LT. These latter cytokines by themselves do not stimulate C1INH production and they do not synergize with IL-6 in this assay (Zuraw, B., and M. Lotz, manuscript submitted).

Immunological analysis of synoviocyte IL-6. To establish whether the activities detected by the different assays in synoviocyte SN were functions of IL-6, we performed antibody neutralization experiments. Fig. 6 shows that antibody raised against human (r)BSF-2/IL-6 completely inhibited the HGF and HSF activity in the culture SN. Preimmune rabbit $\mathrm{IgG}$, at identical concentrations, did not alter these activities. To further characterize the synoviocyte-derived IL-6 proteins, immunoprecipitation of $\left[{ }^{35} \mathrm{~S}\right]$ methionine-labeled synoviocyte, skin fibroblast, and monocyte $\mathrm{SN}$ was performed. The immunoprecipitates contained predominant proteins which migrated as a doublet between 23 and $30 \mathrm{kD}$ in $15 \%$ SDS polyacrylamide gels in (Fig. 7), which is consistent with the known molecular mass of IL-6 $(15,32)$. This doublet was detectable in the unstimulated $\mathrm{SN}$ and was significantly enhanced by stimulation with IL-1. The bands were blocked when the antiserum was preincubated with an excess of (r)BSF-2/IL-6 before immunoprecipitation, confirming that these bands are IL-6. The figure also shows that the proteins precipitated from synoviocyte, skin fibroblast, and monocyte culture SN by this antiserum had identical electrophoretic migration patterns.

IL-6 activity in synovial fluids. Finally, we examined the IL-6 content of a series of synovial fluids. The results in Fig. 8 show that high levels of IL- 6 activity could be detected in all of the rheumatoid arthritis synovial fluids tested (mean $5,288 \pm 1,729$ [SE] $\mathrm{U} / \mathrm{ml}$ ). High levels were also found in fluids from other inflammatory arthropathies. The levels found in psoriatic arthritis, for instance, were not significantly different $(3,806 \pm 2,418 \mathrm{U} / \mathrm{ml}, P=0.48)$ from those in rheumatoid arthritis. In contrast, the IL-6 content of osteoarthritis fluids, although clearly detectable, was significantly lower than that of rheumatoid arthritis $(490 \pm 324 \mathrm{U} / \mathrm{ml}, P=0.0281)$.

\section{Discussion}

These experiments have examined the production of IL- 6 by synoviocytes and the effects of this cytokine on cells that are involved in local and systemic manifestations of arthritis. The 


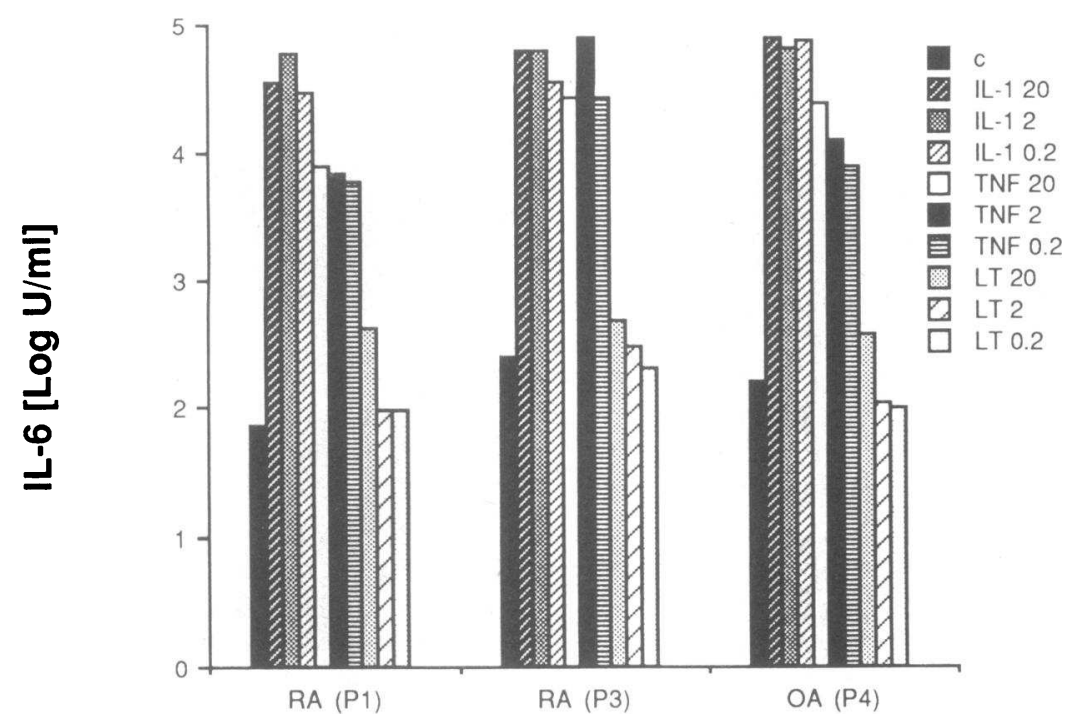

Synoviocytes
Figure 3. Cytokine regulation of synoviocyte IL-6 production. Synoviocytes from rheumatoid arthritis $(R A)$ or osteoarthritis $(O A)$ were cultured in medium supplemented with $1 \%$ FCS alone $(c)$ or with IL-1, TNF- $\alpha$, or LT at the concentrations indicated $(\mathrm{ng} / \mathrm{ml})$. The supernatants were collected after $2 \mathrm{~d}$. IL-6 activity was assayed as proliferation of hybridoma cells. The results are mean values of triplicates (SE $<15 \%)$ of three representative experiments. results show that IL- 6 is produced constitutively by synoviocytes when cultured in the presence of serum and that its synthesis can be upregulated by IL- 1 , TNF- $\alpha$, and, to a lesser extent, by LT. Synoviocyte-derived IL- 6 is able to induce hybridoma-plasmacytoma proliferation as well as immunoglobulin and acute-phase protein synthesis.

Several cytokines have been detected in synovial fluids or in synoviocyte secretions. IL-1 has been identified in rheumatoid arthritis synovial fluids and smaller quantities were found

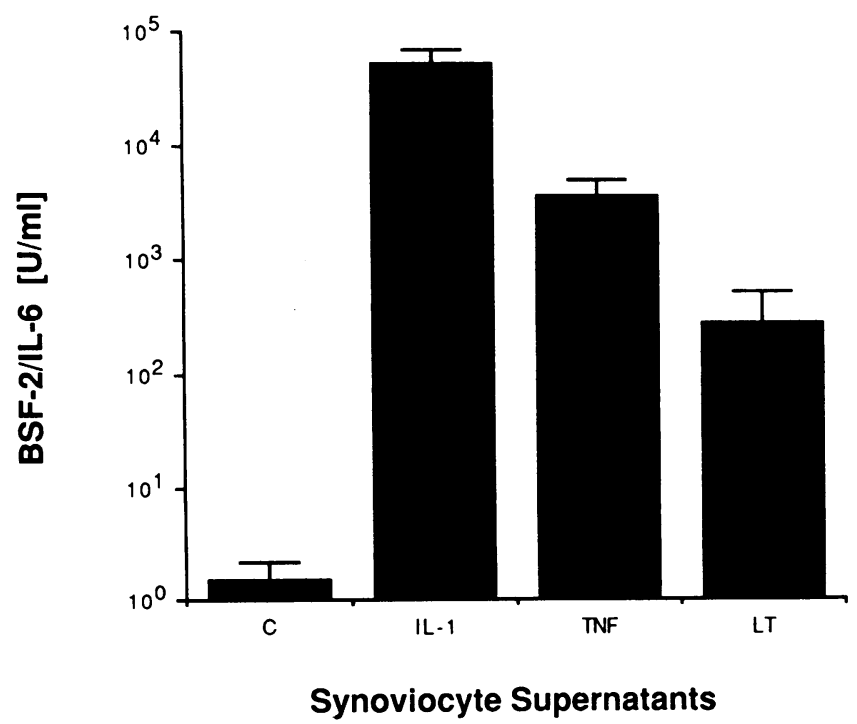

Figure 4. Ig production induced by synoviocyte-derived IL-6 (BSF-2). Synoviocytes from rheumatoid arthritis or osteoarthritis were cultured in medium supplemented with FCS alone $(C)$ or with IL-1, TNF, or LT $(20 \mathrm{ng} / \mathrm{ml})$. After $3 \mathrm{~d}$, the supernatants were collected and assayed for IgG induction in the human lymphoblastoid cell line CESS. The results are mean values of three experiments, each in triplicates. They are compared to a standard curve with IL-6 ([r]BSF-2) and expressed in units per milliliter. Error bars represent the $\mathrm{SE}$ of the three experiments. in fluids from osteoarthritis patients (33-35). In addition, synoviocytes have been shown to produce IL-1 $(36,37)$. IL-2 has also been shown to be present in rheumatoid arthritis synovial fluids by some groups $(38,39)$. Current concepts of the pathogenesis of arthritis, indicate that IL-1 (reviewed by Miossec [9]) and TNF- $\alpha(10,11,40,41)$ are important mediators of local and systemic inflammatory responses. However, although IL- 1 and TNF- $\alpha$ can modulate B cell differentiation at an early phase (42) and induce the production of some acute-phase

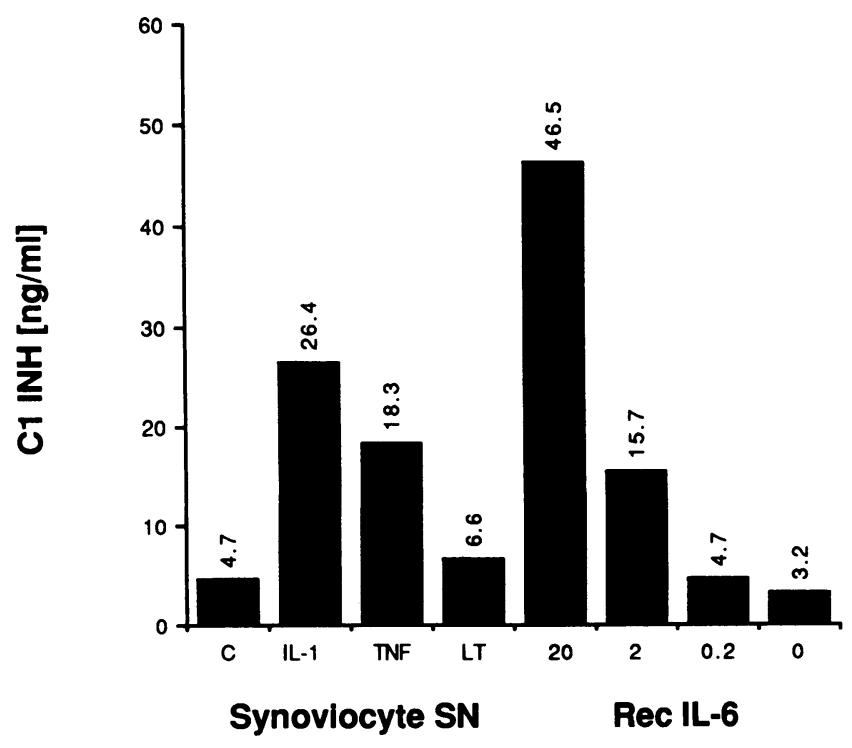

Figure 5. Induction of the acute phase protein $\mathrm{C} 1 \mathrm{INH}$ by synoviocyte-derived IL-6. Rheumatoid arthritis synoviocytes were cultured in medium supplemented with FCS alone $(C)$ or with IL-1, TNF- $\alpha$, or LT $(20 \mathrm{ng} / \mathrm{ml})$. After $3 \mathrm{~d}$ the SN were collected and assayed for C1INH induction in the hepatoma cell line HepG2. The results are mean values of triplicates ( $\mathrm{SE}<10 \%$ ) of a representative experiment. They are compared to various doses of a standard IL-6 (U/ml). 


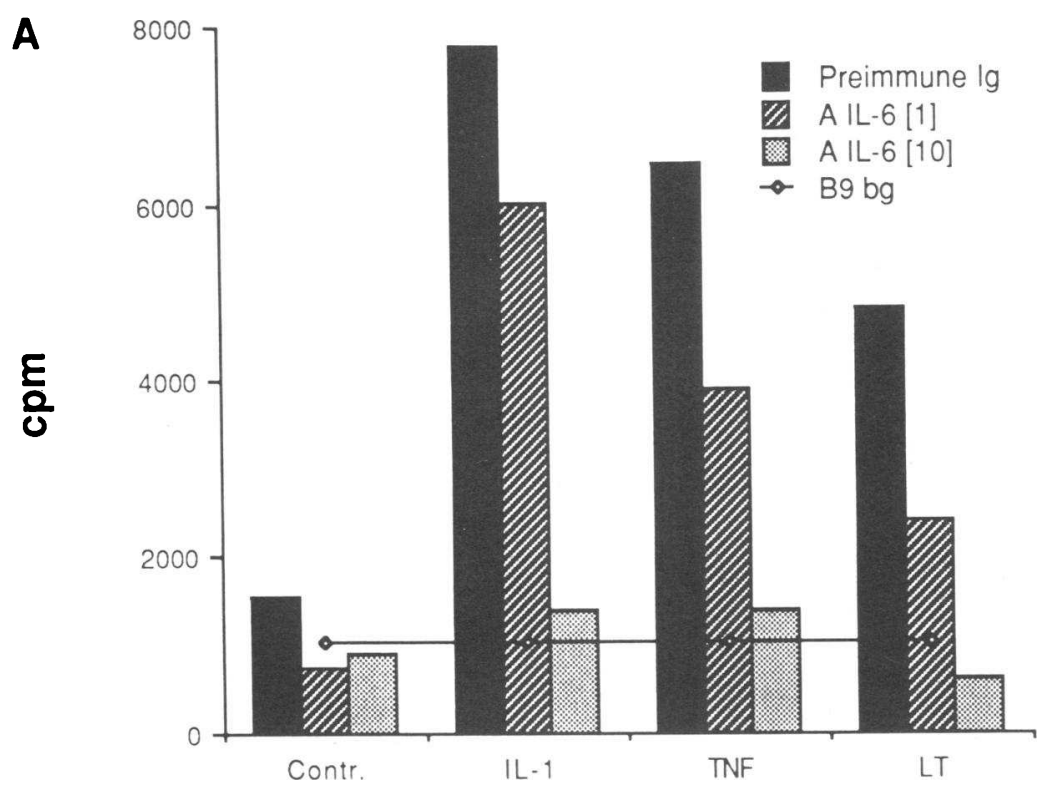

Synoviocyte Supernatants

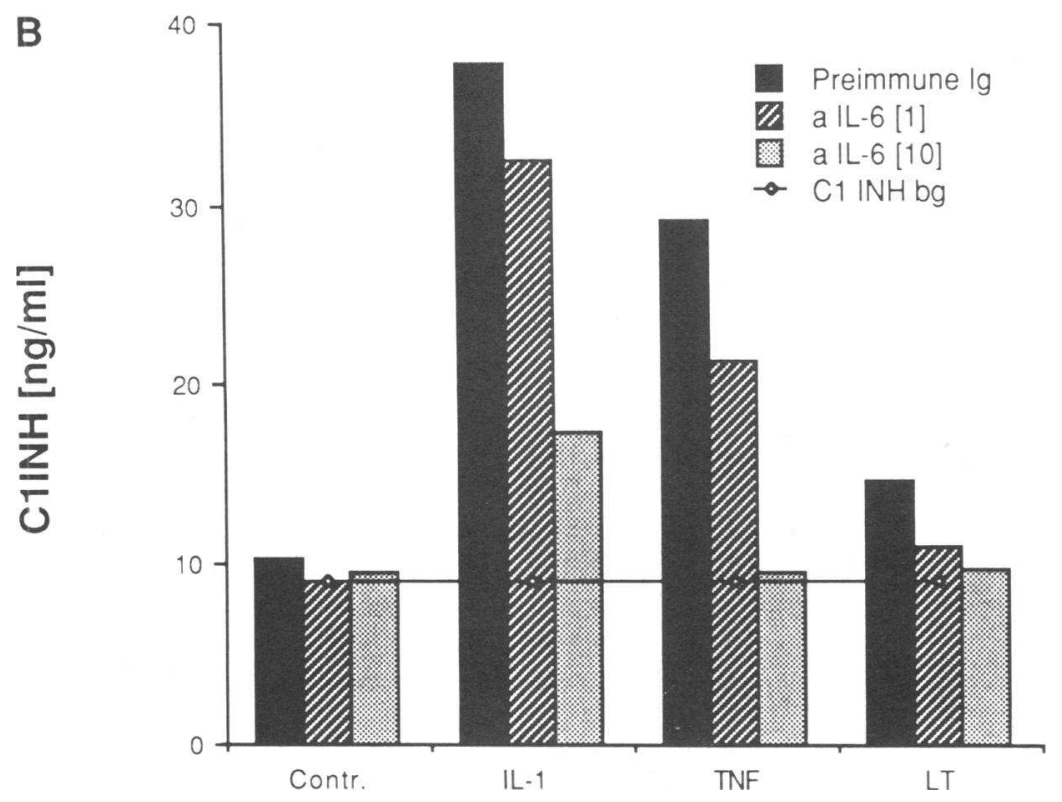

Synoviocyte Supernatants
Figure 6. Antibody neutralization of HPGF/IL-6 and HSF/IL-6. SN were obtained by culturing rheumatoid arthritis synoviocytes in medium alone (Contr.) or with IL-1, TNF- $\alpha$, or LT $(20 \mathrm{ng} / \mathrm{ml})$. They were tested on $\mathrm{B} 9.9$ cells for induction of proliferation $(A)$ and for $\mathrm{Cl}$ esterase inhibitor (C1INH) induction on HepG2 cells $(B)$ at a dilution of 1:50 in presence of the indicated concentrations $(\mu \mathrm{g} / \mathrm{ml})$ of polyclonal antibody to IL-6 (IgG fraction) or preimmune rabbit immunoglobulins. The background of each experiment (B9.9 proliferation and HepG2 C1INH production in the presence of medium without added $\mathrm{SN}$ ) is indicated (B9.9 bg or $\mathrm{CIINH} \mathrm{bg}$ ). Results are mean values of triplicates $(\mathrm{SE}<15 \%)$. proteins (43-45), the spectrum of their effects cannot completely explain the changes seen in inflammatory arthropathies. Furthermore, compared to the levels of IL-6 (mean of $5,200 \mathrm{U} / \mathrm{ml}$ in rheumatoid arthritis which corresponds to 42 $\mathrm{ng} / \mathrm{ml}(\mathrm{r}) \mathrm{BSF}-2)$, much smaller levels of these mediators have been found in synovial fluids.

IL-1 can induce the synthesis of only some acute phase proteins by hepatocytes (43-45). For example, IL-1 does not alter the production of fibrinogen, $\alpha_{2}$-macroglobulin, cysteine proteinase inhibitor, and C1INH. Recently, IL-6 has been shown to be a major HSF that is capable inducing a wide spectrum of acute-phase proteins (19). The results presented here clearly show that synoviocyte-derived IL-6 is indeed able to act as an inducer of acute-phase proteins, providing a rational basis for the acute phase response that regularly accompanies various types of synovitis.

Rheumatoid arthritis is characterized by an increase in B cell activity, as indicated by the large number of B lymphocytes and plasma cells infiltrating the synovium $(46,47)$ and by the presence of hypergammaglobulinemia (1). Rheumatoid arthritis synovial tissues actively produce immunoglobulins (48) and rheumatoid factor (7), which are thought to contrib- 


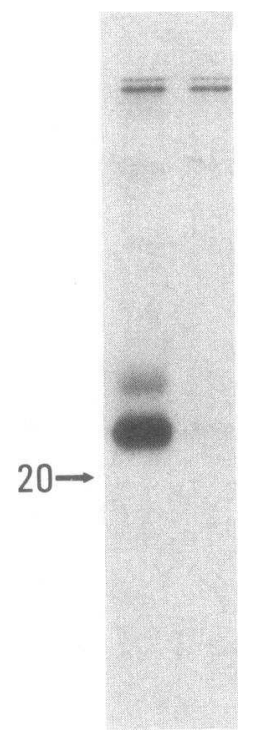

IL-1 C

RA Synov.

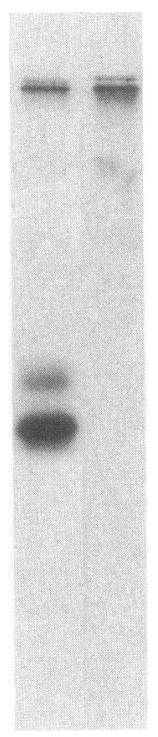

IL-1 C

Skin Fibr.

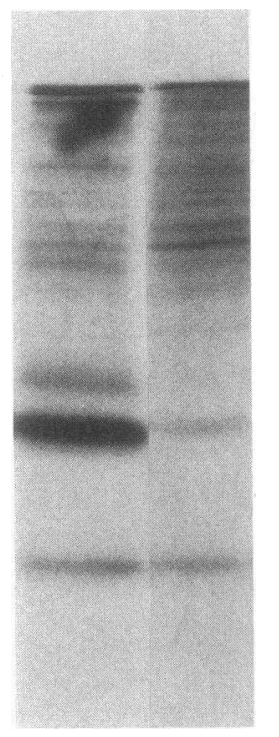

IL-1 C

Monocytes
Figure 7. Immunoprecipitation of IL-6 produced by synoviocytes, skin fibroblasts, and monocytes. SN were obtained by culturing rheumatoid arthritis synoviocytes $\left(10^{5} / \mathrm{ml}\right)$, skin fibroblasts $\left(10^{5} / \mathrm{ml}\right)$, or monocytes $\left(4 \times 10^{5} / \mathrm{ml}\right)$ in methionine-free medium containing $1 \%$ FCS and $\left[{ }^{35} \mathrm{~S}\right]$ methionine in the presence of IL-1 $(2 \mathrm{ng} / \mathrm{ml})$ or unstimulated $(C)$. The labeled proteins were immunoprecipitated with a polyclonal antibody to IL-6 and protein A agarose. Proteins were then separated on $15 \%$ SDS polyacrylamide gels. Autoradiography was performed after impregnation in 2,5-diphenyloxazole-dimethylsulfoxide.

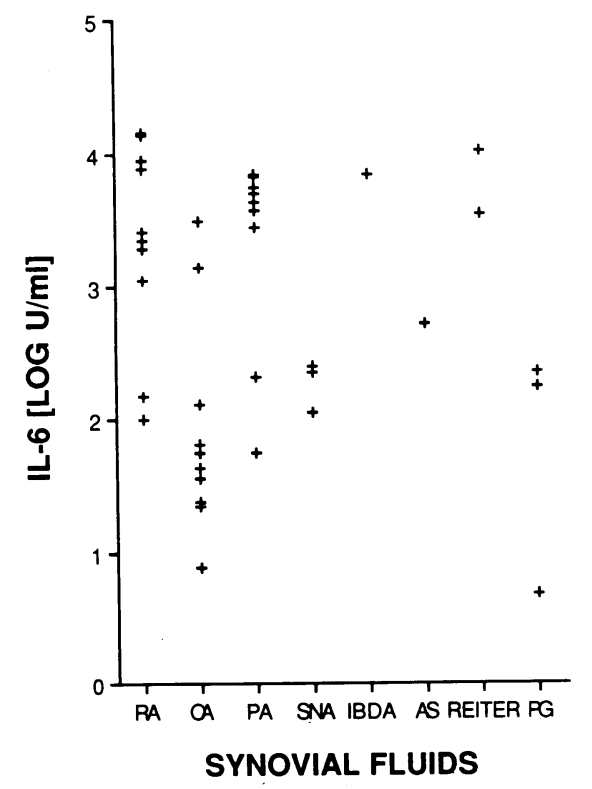

Figure 8. IL-6 activity in synovial fluids. Synovial fluids were collected from patients suffering from different arthropathies: Rheumatoid arthritis $(R A)$, osteoarthritis $(O A)$, psoriatic arthritis $(P A)$, seronegative rheumatoid arthritis $(S N A)$, arthritis associated with inflammatory bowel disease (IBDA), ankylosing spondylitis $(A S)$, Reiter's syndrome $(R E I T E R)$, and pseudogout $(P G)$. The fluids were serially diluted five times and assayed for IL-6 as proliferation of the B9.9 hybridoma cells. Each point represents a different patient. Results are mean values of triplicates ( $\mathrm{SE}<15 \%$ ). They are compared to a standard IL-6 ([r]BSF-2). Units of IL-6 are shown on a $\log ^{10}$ scale. ute to localized immune complex deposition. We show here that the IL-6 produced by synoviocytes stimulates immunoglobulin secretion. Considering the high levels of IL-6 activity that are produced by synoviocytes, this cytokine is therefore likely to play an important role in the hypergammaglobulinemia and rheumatoid factor production seen in rheumatoid arthritis. Based on its function as plasmacytoma growth factor, IL-6 may also promote the plasma cell infiltration seen in rheumatoid synovium (5). It has been demonstrated that some tumors such as cardiac myxoma, cervical cancer and bladdercell carcinoma can release large amounts of IL-6 and that patients bearing these tumors may display autoimmune phenomena and autoantibody production $(30,49,50)$. However, the levels of IL- 6 found in classical rheumatoid arthritis are comparable to those found in seronegative rheumatoid arthritis or in psoriatic arthritis, which feature hypergammaglobulinemia but do not express autoantibodies. IL-6 may therefore be a general stimulus for antibody synthesis in vivo, whereas the specific spectrum of (auto)antibodies is determined by additional factors.

Although not directly tested in this study, it is likely that synoviocyte-derived IL-6 may also contribute to recruitment of cells that participate in the localized inflammatory process. In this aspect, IL-6 again appears to be a more important mediator than IL- 1 since IL-6 and IL-3 act synergistically in supporting proliferation of hematopoietic stem cells, whereas IL-1 has only minimal effects on this response (22).

The fact that constitutive production of IL- 6 by synoviocytes, which was dependent on the presence of serum, persisted at least $7 \mathrm{wk}$ in tissue culture and that skin fibroblasts also produce IL-6 spontaneously suggests that in vivo activation cannot account for the in vitro production of the cytokine. Monocytes have also been shown to produce IL- 6 when cultured in medium containing FCS (51). The factors in serum that are necessary for IL- 6 synthesis have not yet been characterized. It has been suggested that albumin is one factor (51) but platelet-derived growth factor (12) and other factors may also be involved. As shown by metabolic labeling and immunoprecipitation, the IL-6 secreted by synoviocytes is newly synthesized. Furthermore, the molecular mass of synoviocytederived IL- 6 is identical to that of IL- 6 produced by monocytes and skin fibroblasts. The synoviocytes from inflammatory (rheumatoid arthritis, ankylosing spondylitis) and from noninflammatory (osteoarthritis, avascular necrosis) diseases produce similar levels of IL- 6 per cell in tissue culture. By contrast, a clear difference in IL-6 content of synovial fluids was noted between the inflammatory arthropathies and osteoarthritis. These divergent levels may be attributed to in vivo activation and to other cells present in the inflamed synovium. Activated monocytes can release IL- 1 and TNF- $\alpha$, which are potent inducers of IL- 6 in fibroblasts $(13,14)$ as well as in monocytes themselves (Fig. 7). Platelet derived growth factor and interferon- $\beta 1$ have also been shown to induce IL- 6 production by fibroblasts (12). Immune complexes composed of self-associated IgG rheumatoid factor have been shown to induce the release of IL-1 by monocytes (52), raising the question whether immune complexes can alter directly IL-6 production. We have already demonstrated that the crystals associated with inflammatory arthropathies (urate, pyrophosphate, and hydroxyapatite) can induce IL-6 production (Guerne, P. A., unpublished results), and it will be of interest to determine whether this effect is direct or mediated by IL-1 $(53,54)$. Lipopolysaccharide has been shown to increase serum IL-6 
activity in vivo (55) and in cultures of human fibroblasts (56), monocytes (19), and endothelial cells in vitro (Jirik, F., et al., manuscript submitted). We have also found that small concentrations of lipopolysaccharide increase IL- 6 production by synoviocytes (data not shown). Finally, preliminary findings indicated that cytomegalovirus infection of synoviocytes markedly enhanced IL-6 synthesis (Lotz, M., unpublished results). This finding is consistent with other reports showing that viral infections augment IL- 6 production by murine fibroblasts (57) and that poly (rl):poly $(\mathrm{rC})$ is a potent inducer of IL-6 synthesis in fibroblasts (14).

It is certainly possible that cells other than synoviocytes contribute to the production of IL-6 in arthropathies. The large numbers of activated monocytes infiltrating the synovium in rheumatoid arthritis can directly release IL-6 (Lotz, M., unpublished results) and endothelial cells may be an additional sources (Jirik, F., et al., manuscript submitted). Nevertheless, synoviocytes may be a major source of IL-6 since they are a physiological component of the joint and are directly located at the site of inflammation and tissue destruction.

It was of interest to see if IL-6 could also enhance collagenase and $\mathrm{PGE}_{2}$ production by synoviocytes, which represents a major action of IL-1 and TNF in the process of joint destruction. Our results showed that IL-6 does not have this property (Guerne, P. A., manuscript in preparation). Experiments are in progress to determine if IL-6, instead, induces the production of tissue inhibitor of metalloproteinases (TIMP), a specific inhibitor of collagenase (58) which is also regulated by IL-1 (59).

In conclusion, we have established synoviocytes as a potent source of IL- 6 in vitro and found that IL- 6 is abundant in synovial fluids of patients with inflammatory arthritis. Synoviocyte-derived IL-6 can enhance hybridoma and plasmacytoma growth, immunoglobulin synthesis, and hepatic acutephase protein production, providing a rational explanation for important local and systemic manifestations of arthritis.

\section{Acknowledgments}

We thank Drs. C. A. Dinarello, T. Hirano, T. Kishimoto, S. C. Clark, and $\mathrm{H}$. M. Shepard for kindly providing cytokines and antisera used in this study.

This study was supported in part by the Swiss Fund for the Biological and Medical Research (P. A. Guerne), by grants AI10386, RR00833, AR25443, and AR21175 from the National Institutes of Health, and by a grant from the Lilly Research Laboratories.

\section{References}

1. Lichtman, M. A., J. H. Vaughan, and C. G. Hames. 1967. The distribution of serum immunoglobulins, anti-gamma-G globulins ("rheumatoid factors") and antinuclear antibodies in white and negro subjects in Evans County, Georgia. Arthritis Rheum. 10:204-209.

2. Young, C. L., T. C. Adamson, J. H. Vaughan, and R. I. Fox. 1984. Immunohistologic characterization of synovial membrane lymphocytes in rheumatoid arthritis. Arthritis Rheum. 27:32-39.

3. Duke, O., G. S. Panay, G. Janossy, L. W. Poulter, and N. Tidman. 1982. An immunohistological analysis of lymphocyte subpopulation and their microenvironment in the synovial membrane of patients with rheumatoid arthritis using monoclonal antibodies. Clin. Exp. Immunol. 49:22-30.

4. Meijer, C., C. B. De Graaf-Reitsma, G. J. Lafefer, and A. Cats. 1982. In situ localization of lymphocyte subsets in synovial membrane of patients with rheumatoid arthritis with monoclonal antibodies. $J$. Rheumatol. 9:359-365.

5. Veys, E. M., P. Hermann, P. Kung, J. Schindler, G. Goldstein,
G. Symoens, and J. Van Wauwe. 1981. Evaluation of T cell subsets with monoclonal antibodies in patients with rheumatoid arthritis. $J$. Rheumatol. 9:25-29.

6. Burmester, G. R., B. Jahn, M. Gramatzki, J. Zacher, and J. R. Kalden. 1984. Activated $\mathrm{T}$ cells in vivo and in vitro: divergence in expression of Tac and la antigens in the nonblastoid small $\mathrm{T}$ cells of inflammation and normal $\mathrm{T}$ cells activated in vitro. J. Immunol. 133:1230-1234.

7. Petersen, J., C. Hellmann, O. J. Bjerrum, T. Ingemann-Hansen, and J. Halkjaer-Kristensen. 1983. IgG rheumatoid factor-secreting lymphocytes in rheumatoid arthritis: evaluation of a haemolytic plaque-forming cell technique. Scand. J. Immunol. 17:471-478.

8. Dayer, J. M., and S. Demczuck. 1984. Cytokines and other mediators in rheumatoid arthritis. Springer Semin. Immunopathol. 7:387-413.

9. Miossec, P. 1987. The role of interleukin-1 in the pathogenesis of rheumatoid arthritis. Clin. Rheumatol. 5:305-308.

10. Dayer, J. M., B. Beutler, and A. Cerami. 1985. Cachectin/ tumor necrosis factor stimulates collagenase and prostaglandin E2 production by human synovial cells and dermal fibroblasts. J. Exp. Med. 162:2163-2168.

11. Saklatvala, J. 1986. TNF $\alpha$ stimulates resorption and inhibits synthesis of proteoglycan in cartilage. Nature (Lond.). 322:547-549.

12. Walther, Z., L. T. May, and P. B. Sehgal. 1988. Transcriptional regulation of the interferon- $\beta 2 / B$ cell differentiation factor BSF- $2 /$ hepatocyte-stimulating factor gene in human fibroblasts by other cytokines. J. Immunol. 140:974-977.

13. Content, J., L. De Wit, P. Poupart, G. Opdenakker, J. Van Damme, and A. Billiau. 1985. Induction of a $26-\mathrm{kDa}$ protein mRNA in human cells treated with an interleukin-1-related leukocyte-derived factor. Eur. J. Biochem. 152:253-257.

14. Van Damme, J., S. Cayphas, G. Opdenakker, A. Billiau, and J. Van Snick. 1987. Interleukin-1 and poly(rI):poly(rC) induce production of a hybridoma growth factor by human fibroblasts. Eur. J. Immunol. 17:1-7.

15. Hirano, T., T. Taga, N. Nakano, K. Yasukawa, S. Kashiwamura, K. Shimizu, K. Nakajima, K. H. Pyun, and T. Kishimoto. 1985. Purification to homogeneity and characterization of human B cell differentiation factor (BCDF or BSFp-2). Proc. Natl. Acad. Sci. USA. 82:5490-5494.

16. Yasukawa, K., T. Hirano, Y. Watanabe, K. Muratani, T. Matsuda, S. Nakai, and T. Kishimoto. 1987. Structure and expression of human B cell stimulatory factor-2 (BSF-2/IL-6) gene. EMBO (Eur. Mol. Biol. Organ.) J. 6:2939-2945.

17. Zilberstein, A., R. Ruggieri, J. H. Korn, and M. Revel. 1986. Structure and expression of cDNA and genes for human interferon- $\beta 2$, a distinct species inducible by growth-stimulatory cytokines. $E M B O$ (Eur. Mol. Biol. Organ.) J. 5:2529-2537.

18. Haegeman, G., J. Content, G. Volckaert, R. Derynck, J. Tavernier, and W. Fiers. 1986. Structural analysis of the sequence coding for an inducible $26-\mathrm{kDa}$ protein in human fibroblasts. Eur. J. Biochem. 159:625-632.

19. Gauldie, J., C. Richards, D. Harnish, P. Lansdorp, and H. Bauman. 1987. Interferon $\beta 2 / B$ cell stimulator factor type-2 shares identity with monocyte-derived hepatocyte-stimulating factor and regulates the major acute phase protein response in liver cells. Proc. Natl. Acad. Sci. USA. 84:7251-7255.

20. Lotz, M., F. Jirik, P. Kabouridis, C. Tsoukas, T. Hirano, T. Kishimoto, and D. A. Carson. 1988. B cell stimulating factor-2/interleukin-6 is a costimulant for human thymocytes and T lymphocytes. $J$. Exp. Med. 167:1253-1258.

21. Takai, Y., G. G. Wong, S. C. Clark, S. J. Burakoff, and S. H. Herrman. 1988. B cell stimulatory factor-2 is involved in the differentiation of cytotoxic T lymphocytes. J. Immunol. 140:508-512.

22. Leary, A. G., K. Ikebuchi, Y. Hirai, G. G. Wong, Y.-C. Yang, S. C. Clark, and M. Ogawa. 1988. Synergism between interleukin-6 and interleukin-3 in supporting proliferation of human hematopoietic stem cells: comparison with interleukin-1 $\alpha$. Blood. 71:1759-1763.

23. Kohase, M., D. Henriksen-DeStefano, L. T. May, J. Vilcek, and 
P. B. Sehgal. 1986. Induction of $\beta 2$-interferon by tumor necrosis factor: a homeostatic mechanism in the control of cell proliferation. Cell. 45:659-666.

24. Klareskog, L., U. Forsum, U. Malmnas Tjernlund, D. Kabelitz, and A. Wigren. 1981. Appearance of anti-HLA-DR-reactive cells in normal and rheumatoid synovial tissue. Scand. J. Immunol. 14:183192.

25. Lotz, M., and B. L. Zuraw. 1987. Interferon- $\gamma$ is a major regulator of C1-inhibitor synthesis by human blood monocytes. J. Immunol. 139:3382-3387.

26. Van Oers, M. H. J., A. A. P. A. M. Van Der Heyden, and L. A. Aarden. 1988. Interleukin-6 (IL-6) in serum and urine of renal transplant recipients. Clin. Exp. Immunol. 71:314-319.

27. Hirano, T., K. Yasukawa, H. Harada, T. Taga, Y. Watanabe, T. Matsuda, S. Kashiwamura, K. Nakajima, K. Koyama, A. Iwamatsu, S. Tsunasawa, F. Sakiyama, H. Matsui, Y. Takahara, T. Taniguchi, and T. Kishimoto. 1986. Complementary DNA for a novel human interleukin (BSF-2) that induces B lymphocytes to produce immunoglobulin. Nature (Lond.). 324:73-76.

28. Muraguchi, A., T. Kishimoto, Y. Miki, T. Kuritani, T. Kaieda, K. Yoshikazi, and Y. Yamamura. 1981. T cell-replacing factor-(TRF) induced IgG secretion in a human B blastoid cell line and demonstration of acceptors for TRF. J. Immunol. 127:412-416.

29. Fong S., J. H. Vaughan, and D. A. Carson. 1983. Two different rheumatoid factor-producing cell populations distinguished by the mouse erythrocyte receptor and responsiveness to polyclonal B cell activators. J. Immunol. 130:162-164.

30. Hirano, T., T. Taga, K. Yasukawa, K. Nakajima, N. Nakano, F. Takatsuki, M. Shimizu, A. Murashima, S. Tsunasawa, F. Sakiyama, and T. Kishimoto. 1987. Human B cell differentiation factor defined by an anti-peptide antibody and its possible role in autoantibody production. Proc. Natl. Acad. Sci. USA. 84:228-231.

31. Laemmli, U. K. 1970. Cleavage of structural proteins during the assembly of the head bacteriophage T4. Nature (Lond.). 227:680685 .

32. Weissenbach, J., Y. Chernajovsky, M. Zeevi, L. Shulmann, H. Soreq, U. Nir, D. Wallach, M. Perricaudet, P. Tiollais, and M. Revel. 1980. Two interferon mRNAs in human fibroblasts: in vitro translation and Escherichia coli cloning studies. Proc. Natl. Acad. Sci. USA. 77:7152-7156.

33. Fontana, A., H. Hengartner, E. Weber, K. Fehr, P. J. Grob, and G. Cohen. 1982. Interleukin-1 activity in the synovial fluid of patients with rheumatoid arthritis. Rheumatol. Int. 2:49-53.

34. Wood, D. D., E. J. Ihrie, C. A. Dinarello, and P. L. Cohen. 1983. Isolation of an interleukin-1-like factor from human joint effusions. Arthritis Rheum. 26:975-983.

35. Bendtzen, K., J. Peterson, J. Halkjaer-Kristensen, and T. Ingemann-Hansen. 1985. Interleukin-1-like activities in synovial fluids of patients with rheumatoid arthritis and traumatic synovitis. Rheumatol. Int. 5:79-82.

36. Dayer, J. M., C. Zavadil-Grob, C. Ucla, and B. Mach. 1984. Induction of human interleukin-1 mRNA measured by collagenaseand prostaglandin E2-stimulating activity in rheumatoid synovial cells. Eur. J. Immunol. 14:898-901.

37. Goto, M., M. Sasano, H. Yamanaka, N. Miyasaka, N. Kamatani, K. Inoue, K. Nishioka, and T. Miyamoto. 1987. Spontaneous production of an interleukin-1-like factor by cloned rheumatoid synovial cells in long term culture. J. Clin. Invest. 80:786-796.

38. Wilkins, J., R. Warrington, S. Sirgudson, and J. Rutherford. 1983. The demonstration of an interleukin-2-like activity in the synovial fluids of rheumatoid arthritis patients. J. Rheumatol. 10:109-113.

39. Lemm, G., and H. Warnatz. 1986. Evidence for enhanced interleukin-2 (IL-2) secretion and IL-2 receptor presentation by synovial fluid lymphocytes in rheumatoid arthritis. Clin. Exp. Immunol. 64:71-79.

40. Bertolini, D. R., G. E. Nedwin, T. S. Bringham, D. D. Smith, and G. R. Mundy. 1986. Stimulation of bone resorption and inhibition of bone formation in vitro by human tumor necrosis factor. Nature (Lond.). 319:516-518.
41. Dinarello, C. A., J. G. Cannon, S. M. Wolf, H. A. Bernheim, B. Beutler, I. S. Figari, M. A. Palladino, and J. V. O'Connor. 1986. Tumor necrosis factor (cachectin) is an endogenous pyrogen and induces production of interleukin-1. J. Exp. Med. 163:1433-1450.

42. O'Garra, A., S. Umland, T. De France, and J. Christiansen. 1988. B-cell factors' are pleiotropic. Immunol. Today. 9:45-54.

43. Gauldie, J., D. N. Sauder, K. P. W. J. McAdam, and C. A. Dinarello. 1987. Purified interleukin-1 (IL-1) from human monocytes stimulates acute phase protein synthesis by rodent hepatocytes in vitro. Immunology. 60:203-207.

44. Koj, A., A. Kurdowska, D. Magielska-Zero, H. Rokita, J. D. Sipe, J. M. Dayer, S. Demczuk, and J. Gauldie. 1987. Limited effects of recombinant human and murine interleukin-1 and tumor necrosis factor on production of acute phase proteins by cultured rat hepatocytes. Biochem. Int. 14:553-560.

45. Baumann, H., V. Onorato, J. Gauldie, and G. P. Jahreis. 1987. Distinct sets of acute phase plasma proteins are stimulated by separate human hepatocyte-stimulating factors and monokines in rat hepatoma cells. J. Biol. Chem. 262:9756-9768.

46. Mellors, R. C., A. Nwolawski, L. Korngold, and L. Sengson. 1961. Rheumatoid factor and the pathogenesis of rheumatoid arthritis. J. Exp. Med. 113:475-484.

47. Munthe, E., and J. B. Natvig. 1972. Complement fixing intracellular complexes of $\mathrm{IgG}$ rheumatoid factor in rheumatoid plasma cells. Scand. J. Immunol. 1:217-223.

48. Smiley, J. D., C. Sachs, and M. Ziff. 1968. In vitro synthesis of immunoglobulins by rheumatoid synovial membrane. J. Clin. Invest. 47:624-632.

49. Bataille, R., and B. Klein. 1987. Autoimmune conditions induced by epithelial solid tumors. Rheumatol. Int. 7:231-233.

50. Sutton, M. G. S. J., L. Mercier, E. R. Giulani, and J. T. Lie. 1980. Atrial myxomas. A review of clinical experience in 40 patients. Mayo Clin. Proc. 55:371-376.

51. Aarden, L. A., E. R. De Groot, O. L. Schaap, and P. M. Lansdorp. 1987. Production of hybridoma growth factor by human monocytes. Eur. J. Immunol. 17:1411-1415.

52. Nardella, F. A., J. M. Dayer, M. Roelke, S. M. Krane, and M. Mannik. 1983. Self-associating IgG rheumatoid factors stimulate monocytes to release prostaglandins and mononuclear cell factor that stimulates collagenase and prostaglandin production by synovial cells. Rheumatol. Int. 3:183-186.

53. Dayer, J. M., V. Evêquoz, C. Zavadil-Grob, M. D. Gryynpas, P. T. Cheng, J. Schnyder, U. Trechsel, and H. Fleisch. 1987. Effect of synthetic calcium pyrophosphate and hydroxyapatite crystals on the interaction of human blood mononuclear cells with chondrocytes, synovial cells, and fibroblasts. Arthritis Rheum. 30:1372-1380.

54. Di Giovine, F. S., S. E. Malawista, G. Nuki, and G. W. Duff. 1987. Interleukin-1 (IL-1) as a mediator of crystal arthritis. Stimulation of $T$ cell and synovial fibroblast mitogenesis by urate crystal-induced IL-1. J. Immunol. 138:3213-3218.

55. Coulie, P. G., S. Cayphas, S., A. Vink, C. Uyttenhove, and J. Van Snick. 1987. Interleukin-HP1-related hybridoma and plasmacytoma growth factors induced by lipopolysaccharide in vivo. Eur. $J$. Immunol. 17:1217-1220.

56. Helfgott, D. C., L. T. May, Z. Sthoeger, I. Tamm, and P. B. Sehgal. 1987. Bacterial lipopolysaccharide (endotoxin) enhances expression and secretion of $\beta 2$ interferon by human fibroblasts. J. Exp. Med. 166:1300-1309.

57. Cayphas, S., J. Van Damme, A. Vink, J. Simpson, A. Billiau, and J. Van Snick. 1987. Identification of an interleukin HP1-like plasmacytoma growth factor produced by $\mathrm{L}$ cells in response to viral infection. J. Immunol. 139:2965-2969.

58. Docherty, A. J. P., A. Lyons, B. J. Smith, E. M. Wright, P. E. Stephens, and T. J. R. Harris. Sequence of human tissue inhibitor of metalloproteinases and its identity to erythroid-potentiating activity. Nature (Lond.). 318:66-60.

59. Murphy, G., J. J. Reynolds, and Z. Werb. 1985. Biosynthesis of tissue inhibitor of metalloproteinases by human fibroblasts in culture. J. Biol. Chem. 260:3079-3083. 